\title{
Chapter 9: The Incorporation of Australian Youth in a Multicultural and Transnational World
}

\author{
Christine Inglis
}

This chapter explores how integration and multiculturalism intersect with, affect and, in turn, are influenced by their encounter with Australian youth. This focus on a social category, rather than being restricted to a particular dimension of incorporation, reflects a realisation that in the modern world youth has emerged as a distinctive social grouping in transition between childhood and adult life with its own cultural features, interests and challenges. Key social changes contributing to the construction of this distinct social group include the extension of universal education, increasing longevity, changes in family formation and the world of work as well as expanding prosperity and consumerism. The age-based definition of 'youth' can extend from 12-35'. In this paper the focus is on those aged from 18-35 who, as legal adults with their schooling behind them, still face the challenge of entering the world of work, and establishing a separate household and family.

As this chapter will argue, the way youth do this in contemporary Australia does not necessarily fit with many of the older assumptions about how those from migrant backgrounds are incorporated into Australian society. While apparently straightforward, the title of this project, Integration and Multiculturalism: A harmonious combination?, allows for diverse interpretations. Both 'integration' and 'multiculturalism' refer to Australian policy responses to diversity. But they also have descriptive and normative or ideological referents which affect the precise conceptual and policy issues to examine in relation to the experiences of youth from diverse ethnic backgrounds. Following a consideration of these and their implications for evaluating the incorporation of ethnic minority youth in Australia, the remainder of the chapter focuses on the young people, their experiences and the dynamics underlying their incorporation in Australian society.

1 Nilan, P and Feixa, C (eds) (2006). Global Youth? Hybrid identities, plural worlds, Routledge, London: 1. 


\section{Sociological perspectives on integration and multiculturalism}

One of the challenges posed by this project is to locate it within the context of social science disciplinary debates. From a sociological perspective these involve theoretical debates surrounding the efforts of theorists to capture the essence of the massive social changes occurring in the 19th century. Their interest focused on the transformation of 'traditional' societies into a modern world in which individual merit and free association replaced a reliance on ascribed status and homogeneity as a basis for stability and social continuity. These changes have prompted a continuing theoretical and empirical interest in how the pre-conditions for ensuring social harmony, if not social survival, can exist within a democratic framework. But, if sociologists within Western industrial societies often ignored the potential significance of ethnically based diversity, the continuing social and political significance of ethnic diversity continued to be evident in other societies ${ }^{2}$. And by the end of the 20th century, as the exponential expansion of migration generated new inter-ethnic encounters and social conflicts, there was a renewed theoretical interest in the social and political significance of ethnic diversity. Underlying this interest were debates concerning the root causes of ethnic conflict. Does it result from the absence of shared culture and values as suggested by theorists such as Durkheim and Parsons? Or is it because of socio-economic inequality and conflicting material interests as those influenced by Marx argue?

By the late 20th century the theoretical debates were broadened to take account of two phenomena whose existence could no longer be ignored. These were globalisation and transnationalism. These processes called into question the previous theoretical focus on 'intact' societies and their states as they highlighted the movements of people, information, ideas, cultural forms and, potentially, conflicts across state and societal borders. A key question associated with globalisation is how these factors transform ethnic groups and their position within society. The transnational paradigm directs attention to the existence of ethnic ties stretching beyond the boundaries of the local/national society and state thus raising questions about their impact on the society of residence and, also, on the 'homeland' and third countries ${ }^{3}$.

\footnotetext{
2 Inglis, C (2000). "The "rediscovery" of ethnicity: Theorising and analysis at the end of the twentieth century', in S Quah and A Sales (eds), The International Handbook of Sociology, Sage, London: 151-170.

3 Dunn, K (2005). A Paradigm of Transnationalism for Migration Studies. New Zealand Population Review, 31(2): 15-31; Inglis, C (2007). Transnationalism in an Uncertain Environment: Relationship between Migration, Policy and Theory. IJMS: International Journal on Multicultural Societies 9, 2: 185-204.
} 
Despite their generality these theoretical debates provide a framework for mid-level theorisation and empirical inquiry into such issues of inter-ethnic relations as:

- Does the continuing existence of ethnic diversity necessarily contribute to internal/domestic social conflict?

- Are ethnic processes and phenomena susceptible to 'management', particularly through government policies?

- If they are susceptible to such management, what type of policies limit or moderate the appearance of social conflict?

In doing so they provide a link between the theoretical and policy levels of debate and analysis, since, once inter-ethnic relations are identified as a social 'problem', the way is open for policy makers to seek appropriate policy responses to overcome social conflict, especially in a manner commensurate with democratic principles. In Australia, as in many other Western industrial societies, assimilation was the dominant policy response until the late 1960s. Like other policy models it includes a descriptive dimension as well as an ideological or normative statement concerning the appropriate outcome to ensure stability and social harmony. Based on research by the Chicago school of sociology in the early 20th century, assimilation theory argued that ethnic minorities would become 'invisible' as they took on the values and behaviours of the larger society. Given that assimilation was viewed as inevitable there was a denial of the need for any active policy interventions by the majority society since the responsibility for change lay with the minority group ${ }^{4}$. Cultural change was at the heart of assimilation theory and highlights its links to theorists such as Durkheim. A similar link to Durkheim's work has been noted in an Australian study addressing the recent interest in social cohesion, if not as a policy model, then certainly as a policy objective and normative outcome ${ }^{5}$. Nevertheless, there remains considerable disagreement about the term and its actual policy focus, although in addition to focusing on the existence of shared values there is also an emphasis on 'commitment' and 'belonging' ${ }^{6}$ which typically carries the connotation that this is the responsibility of the minority group member.

In Australia, following the criticisms of assimilation policy based on the disjuncture between its theorising and the social reality of immigrant settlement experiences, integration was briefly adopted in the late 1960s as its replacement. Although integration policy was never fully articulated and was soon replaced in the 1970s by multicultural policy, its underlying premises appeared to be

4 Martin, J (1978). The Migrant Presence. Allen and Unwin, Sydney.

5 Jupp, J, Nieuwenhuysen, J and Dawson, E (eds). (2007). Social Cohesion in Australia, Cambridge University Press, Melbourne.

6 Markus, A and Kirpitchenko, L (2007). Conceptualising Social Cohesion. In J Jupp, J Nieuwenhuysen and E Dawson (eds), Social Cohesion in Australia, Cambridge University Press, Melbourne: 21-32. 
that minority members might retain their cultural practices in the privacy of the home even if, in public, they were still expected to conform to Australian society and institutions. More recently, following its appearance in European migration debates, integration has once again entered Australian policy discussions. The European Union now describes integration as a 'two way' process involving change by both the minority and majority groups in society ${ }^{7}$. However, there remains in Europe a tendency for supporters of 'integration' to assign to it assimilationist expectations and objectives in which the one-way process is the responsibility of the minority individual ${ }^{8}$. This is not surprising since 'integration' played a prominent role in the structural-functional theory of Talcott Parsons which emphasised the importance of social consensus and underplayed the role of power in social relations.

Contrasting with the emphasis on shared culture and values evident in assimilation theories and policies and the associated social cohesion and integration approaches are policies addressing social exclusion and its obverse social inclusion. The theoretical underpinnings of these approaches derive from neo-Marxian class theories of society which identify power relations and material inequalities as key factors influencing inter-ethnic relations. The policy priorities to achieve stability and harmony thus focus on overcoming material differences and inequalities and removing the barriers to the participation of minority group members in key social institutions and structures. Since its election in 2007 the Labor government has announced an Australian Social Inclusion Agenda intended to reduce disadvantage, increase social, civil and economic participation and to give people a greater say in identifying their needs and participating in policy making while also having the responsibility to take advantage of available opportunities ${ }^{9}$. While the Agenda targets a broad range of social groups and is not limited to ethnic minorities it obviously has relevance to policies relating to inter-ethnic relations.

The importance of overcoming ethnic disadvantage was one of the key factors leading to Australia's shifting in the 1970s from integration to multicultural policy. As multicultural policy has evolved over four decades, there have been changes in the emphases placed on overcoming disadvantage and the support and maintenance of cultural diversity. This policy focus on both disadvantage and cultural diversity is a distinctive feature of Australian and Canadian

\footnotetext{
7 European Commission (2005). Communication from the Commission to the Council, the European Parliament, the European Economic and Social Committee and the Committee of the Regions: A common agenda for integration-framework for the integration of third-country nationals in the European Union.

8 Brubaker, R (2001). The Return of Assimilation? Changing Perspectives on Immigration and Its Sequels in France, Germany, and the United States. Ethnic and Racial Studies, 24 (4): 531-548; Wright, S (2008). Citizenship Tests in Europe - Editorial Introduction. IJMS: International Journal on Multicultural Societies, vol 10, 1: 109.

9 Australian Government (2009). Social Inclusion Principles for Australia. Retrieved 21 August 2009.
} 
multicultural policies ${ }^{10}$. In both countries multicultural policies were developed in response to political considerations which, in a marked departure from the descriptive dimensions of the assimilation model, recognised the ongoing social and political significance of diverse ethnic groups. This descriptive difference highlighted the need for policies which provided ethnic minorities with opportunities for incorporation while at the same time avoiding conflict and ensuring social stability. An important dimension of these policies was that the responsibility for change shifted from the minority to the majority and, in particular, involved institutional reform to reflect the diversity in the society. Initially conceived as a policy for migrants, by 1989 the National Agenda for a Multicultural Australia ${ }^{11}$ marked a major normative and ideological shift as it proclaimed that multiculturalism was a policy for all Australians. The distinctive ideological feature of the policy was describing cultural diversity as a benefit to the society as a whole. In itself, this was a major change from commonly held views that such diversity is a potential threat to social stability and survival.

\section{Dimensions of incorporation}

The present examination of the experiences of Australia's ethnically diverse youth takes place after nearly four decades, or two generations, of multicultural policies. Because of the ambiguities surrounding 'integration' and its key dimensions and to avoid confounding it with assimilation, this chapter uses the term 'incorporation' rather than 'integration' when exploring how young Australians (both overseas and locally born) from diverse ethnic backgrounds are incorporated into Australian society. The experiences of the locally born second generation in Australia and elsewhere attract considerable theoretical interest as they provide a litmus test to evaluate the impact of official policies for managing diversity. This is because as they have grown up and been locally educated it is assumed they have overcome barriers to incorporation such as poor English and overseas qualifications which may penalise their overseas-born peers. They also largely avoid the material and social disruptions experienced by the overseas born other than those referred to as the ' $1 b$ ' or ' 1.5 ' generation who arrived in Australia when very young and were also educated in Australia.

Despite the lack of consensus as to the conceptual framework to privilege in evaluating the process of incorporation, there is nevertheless considerable agreement concerning the types of phenomena which are important dimensions in the settlement process. This is exemplified in the way the actual dimensions identified in the detailed seven stage assimilation model developed by Milton

10 Wieviorka, M (1998). Is multiculturalism the solution? Ethnic and Racial Studies, 21, 5: 880-910.

11 Office of Multicultural Affairs (1989). National Agenda for a Multicultural Australia. Canberra: Australian Government Publishing Service. 
Gordon $^{12}$ are still widely used as indicators even if set within a different theoretical framework ${ }^{13}$. Three main dimensions of incorporation are examined here. The first concerns the extent of socio-economic disadvantage experienced by ethnic minority groups. This involves exploring education and labour market involvement, since economic and educational capital directly affect the material circumstances of individuals and their ability to participate in society. The second dimension involves individuals' social networks, cultural practices and values. It addresses the extent to which individuals' social relations are constrained within their own ethnic group or extend across other minority and majority groups. These relations and cultural attributes also have the potential to provide social and cultural capital which complement individuals' material resources and economic capital. However, whether such capital exists depends on the institutional structures of the wider society which construct the capital 'markets'. Here prejudice and discrimination targeting the minority groups are also relevant. The third dimension of incorporation examined here involves citizenship, identification and other subjective aspects of belonging which are affected by prejudice and discrimination in the wider society. The impacts of globalisation and transnationalism are also potentially important for the ways in which they foster and sustain linkages and attachments outside Australia. They do this through the new technologies which have greatly enhanced opportunities for immediate and cheap international contacts involving the internet and international travel.

\section{Ethnic youth research}

Before examining each of these dimensions it is important to note that one of the major features of research involving Australian youth, and especially those of immigrant background, has been its problem orientation and, in particular, a focus on how young people are 'at risk' ${ }^{14}$. Initially, the area of greatest concern involved the first dimension of incorporation, the educational participation and attainment of those from non-English speaking migrant backgrounds. Because of their linguistic differences, and how these were taken as indicators of other cultural differences, these young people were often depicted as being torn between the two worlds variously described as 'home' and 'school'; the

12 Gordon, M (1964). Assimilation in American Life. Oxford University Press, NY.

13 Kaya, A (2009). Islam, Migration and Integration: The Age of Securitization. Palgrave Macmillan, Basingstoke: 35 .

14 Butcher, M and Thomas, M (eds) (2003). Ingenious: Emerging youth cultures in urban Australia. Melbourne: Pluto Press; Sherington, G (1995). Youth Policy and Ethnic Youth: A history, in C Guerra and R White (eds), Ethnic Minority Youth in Australia: Challenges and myths, National Clearinghouse for Youth Studies, Hobart: 25-34; White, R (ed) (1999b). Australian Youth Subcultures: On the margins and in the mainstream. Australian Clearinghouse for Youth Studies, Hobart. 
culture of the 'homeland' and Australia; or traditional and modern values ${ }^{15}$. These cultural differences were seen as creating problems for them in adjusting to school and succeeding educationally. These included the view that they were more prone to become school dropouts as problems at school were exacerbated by conflict with their own, often poorly educated, parents who brought different norms and expectations to Australia. From this starting point youth research separated in two directions. One focused on the extent of educational inequality amongst ethnic minorities while the second was concerned with their identity formation and how this was linked to their involvement in the home and wider Australian society.

By the 1970s educational inequality was seen as a major policy issue which affected girls, working class and rural students as well as those from ethnic minority backgrounds ${ }^{16}$. The particular problems facing students from Non English Speaking Backgrounds (NESB) provided a major impetus for the development of a range of migrant and multicultural education policy innovations ${ }^{17}$. The extent to which social class rather than ethnic background was the major factor in the patterns of educational disadvantage involving particular immigrant background children was never really resolved ${ }^{18}$. By the 1990s, the concerns about educational disadvantage for those of ethnic minority backgrounds were less commonly heard, reflecting evidence that, perhaps as a result of the various multicultural educational innovations as well as the increasing arrival of skilled professional migrants with high levels of educational resources and educational capital, there was decreasing evidence of clear patterns of ethnic inequality involving the non-Indigenous population.

The first major collection of papers on ethnic minority youth which addressed the second research focus covered a range of youth experiences with the majority of papers exploring in detail the diverse experiences of young people ${ }^{19}$. It also highlighted the limitations of the overly simplistic conflict view of relations between ethnic minority youth and their parents. This was based on an essentialist and static model of socialisation and cultural diversity implicit in the 'Between Two Worlds' approach which ignored the role of individual agency involved in identity construction. Also focusing on the agency involved

15 Brotherhood of St Laurence (1971). Two Worlds: School and the Migrant Family. Stockland Holdings, Melbourne.

16 Interim Committee for the Australian Schools Commission (1973). Schools in Australia: Report of the Interim Committee for the Australian Schools Commission, May 1973, [the Karmel Report]. AGPS, Canberra.

17 Martin, J (1978). Op cit.

18 Jakubowicz, A (1985). Education and Ethnic Minorities- Issues of Participation and Equity. Canberra: National Advisory and Coordinating Committee on Multicultural Education; Poole, M E (1981). Educational Opportunities for Minority Groups: Australian Research Reviewed. In J Megarry (ed), Education of Minorities: World Yearbook of Education. Kogan Page, London.

19 Guerra, C and White, R (eds) (1995). Ethnic Minority Youth in Australia: Challenges and Myths. National Clearing House for Youth Studies, Hobart. 
in ethnic minority youth's daily lives, cultural practices and identities was another collection of papers which addressed the way in which the digital revolution, linked to globalisation and transnationalism, played a major role in the life of young men and women from immigrant backgrounds ${ }^{20}$.

However, much of the recent research has focused on the problems of transition into the adult world within the older model of conflict between two worlds. In the case of young women, especially those perceived to be from certain 'traditional' cultures, the focus has been on conflicts between them and their families with regard to their future gendered roles as wives and mothers as well as their inability to participate in social activities outside the family and home with the same freedom as their brothers or friends from other backgrounds. This has been described as the 'being allowed to go out issue ${ }^{21}$. In the case of young men, much of the focus has been on youth 'gangs'. This research has its origins in public concerns about the potential of young men from ethnic minority backgrounds to form gangs which constitute potential threats to social harmony (if not violence and criminal activity) and, more recently, even to national security. Encounters with police have been seen as a particular source of tension and the media has also been implicated in promoting the dangers associated with these gangs whose values are portrayed as opposed to those of the wider society. In Australia, research on ethnic youth gangs began in the $1990 \mathrm{~s}^{22}$. In fact, one of the main conclusions from the studies undertaken involving a number of different ethnic groups in Melbourne was that 'most often the 'gang' is simply a group of like-minded young people who enjoy each other's company, and who share support and life experiences in common ${ }^{23}$. Research in Sydney has been concentrated in the outer western suburbs and in particular on young Lebanese. It coincides with extensive media reporting of a series of particularly violent gang rapes linked to Lebanese youth in the late $1990 s^{24}$. Subsequently, the events of 9/11, the commencement of the War on Terror and the Cronulla Riots of 2005 have led to a targeting of Muslims by the

\footnotetext{
20 Butcher, $\mathrm{M}$ and Thomas, M (2003). Op cit.

21 Tsolidis, G (1986). Educating Voula: A report on non-English-speaking background girls and education. Melbourne: Ministerial Advisory Committee on Multicultural and Migrant Education: 59.

22 Pe-Pua, R (1999). Youth and Ethnicity: Images and constructions, in R White (ed) (2000), Op cit: 130-137; White, R, Perrone, S, Guerra, C and Lampugnani, R (1999). Ethnic Youth Gangs in Australia: Do they exist? Overview Report. Australian Multicultural Foundation, Melbourne.

23 White, R (1999a). Youth Gangs, in R White (ed) (2000), Op cit: 44.

24 Collins, J, Noble, G, Poynting, S and Tabar, P (2000). Kebabs, Kids, Cops and Crime: Youth, Ethnicity and Crime. Pluto Press, Annandale; Noble, G, Poynting, S and Tabar, P (1999a). Lebanese Youth and Social Identity, in R White (ed) (2000), Op cit: 130-137; Noble, G, Poynting, S and Tabar, P (1999b). Youth, Ethnicity and the Mapping of Identities: Strategic essentialism and strategic hybridity among male Arabic-speaking youth in South-western Sydney. Communal/Plural, 7(1): 29-44; Poynting, S (2000). Ethnicising Criminality and Criminalising Ethnicity, in J Collins and S Poynting (eds), The Other Sydney: Communities, Identities and Inequalities in Western Sydney, Common Ground Publishing, Altona: 63-78.
} 
media, public and government which has led to a continuing research focus on Muslim and, in particular, Lebanese youth and the way they have been depicted in the media and by police ${ }^{25}$.

\section{Australia's multicultural youth}

Before examining the contemporary patterns of incorporation among Australia's multicultural youth it is useful to know who they are and where they come from. In 2006 the census showed that those aged between 18-35 were a quarter (24.8 per cent) of Australia's population. Within this age group it is useful to distinguish two sub-groups. The first are those aged 18-24 who have normally completed their schooling and are in the process of moving into adult life while frequently continuing their education and commencing work. The second group, those aged between 25 and 35, are included given the new trends to extend education and to delay the start of careers and family life.

These Australian young people reflect the ethnic diversity in the wider population with 27 separate ancestries having at least 10,000 young Australians identifying with them in the 2006 Census (Figure 1). Among the overseas born first generation these represent 80 per cent of the total population. However, among the Australian born, second or higher generation, this figure increases to over 97 per cent, reflecting the more recent diversification of immigration source countries which has resulted in many more small ancestry groups in the first generation. Also very important is the way large numbers of the Australian born chose to identify their primary ancestry as 'Australian' rather than identifying with that of their overseas-born parents. The size of the major ancestry groups differs considerably. The largest group is the English closely followed by Australians then Irish, Italians and Chinese. The greater prominence of both Australians and Australian Aboriginals in the locally born population highlights how important Australian birth is to both identities. In other ancestry groups the greater or lesser prominence of the overseas or locally born reflects changes in the major source countries of Australia's immigrant population. Thus, whereas among Asian groups the first generation outnumbers the Australian born, the reverse is the case in European groups who commenced migration to Australia earlier.

25 Poynting, S and Morgan, G (eds) (2007). Outrageous! Moral panics in Australia. Hobart: Australian Clearing House for Youth Studies Publishing; Poynting, S, Noble, G, Taylor, C and Collins, J (2004). Bin Laden in the suburbs: Criminalising the Arab other. Institute of Criminology, Sydney. 


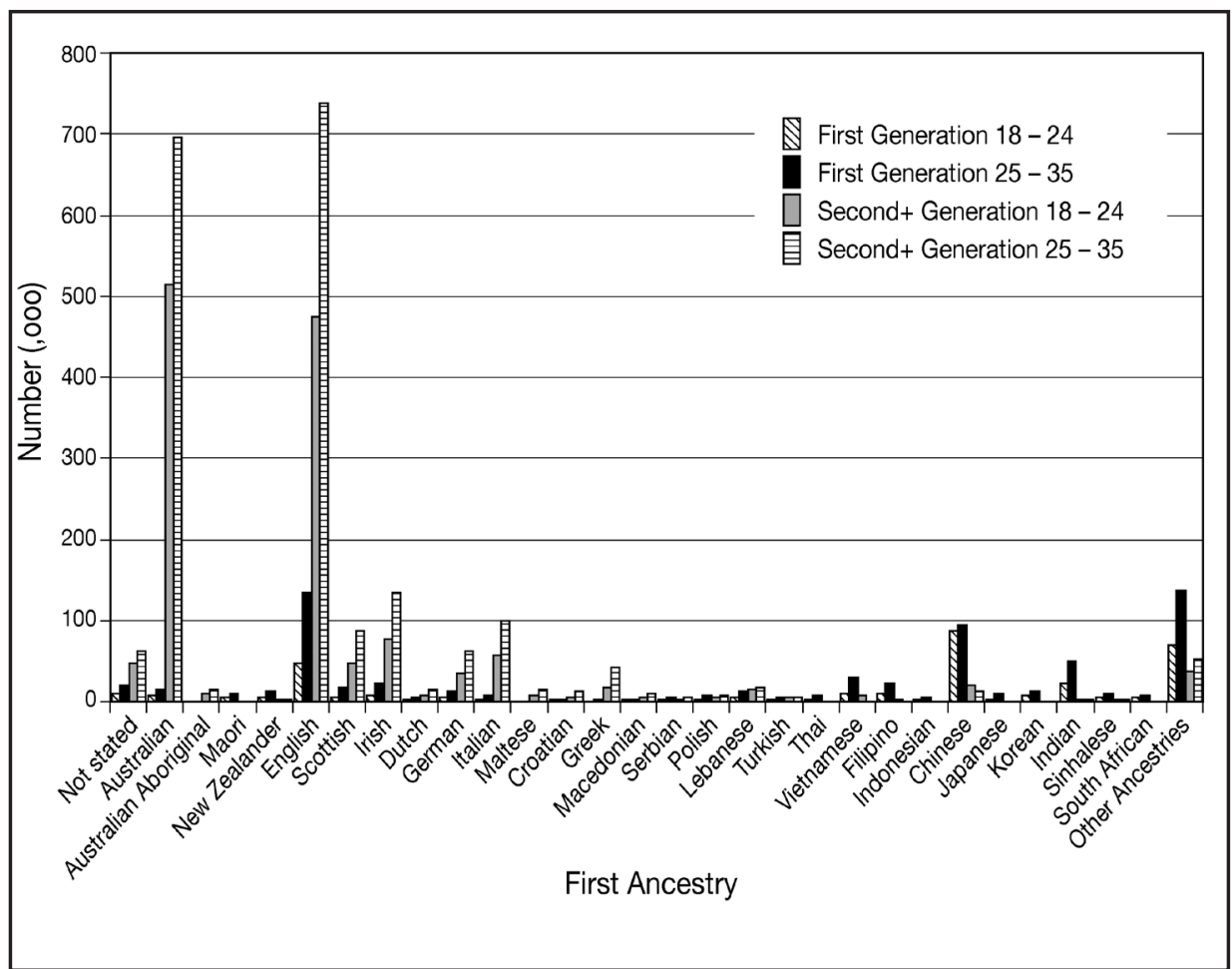

Figure 1 Selected ancestry by generation and age, 2006

Figure 2 shows the percentage of the 18-35 year olds from selected ancestries who reported having only a single ancestry. Among the overseas-born first generation there was considerable diversity in the extent to which they reported having more than one ancestry. Among the Australian born ${ }^{26}$ with the exception of Australian, Aboriginal and Greek ancestry groups, there was an increased likelihood that the young people acknowledged more than one ancestry, which points to an increasing incidence of inter-ethnic marriage, itself an indicator of incorporation ${ }^{27}$. By the second generation there was a decline in the number of ancestry groups where more than 90 per cent of young people reported only having a single ancestry. Apart from Australian Aboriginals and Greeks the other ancestry groups where more than 90 per cent of young people reported having only a single ancestry were the Macedonians, Lebanese, Turkish, Vietnamese and Koreans.

26 The Census CData2006 used in this analysis did not allow a distinction between the second-generation and third-generation groups where the individual and both their parents were born in Australia. Hence the term $2+$ generation is used to refer to those born in Australia when discussing the census data.

27 See chapter 6 in this volume by Siew-Ean Khoo. 


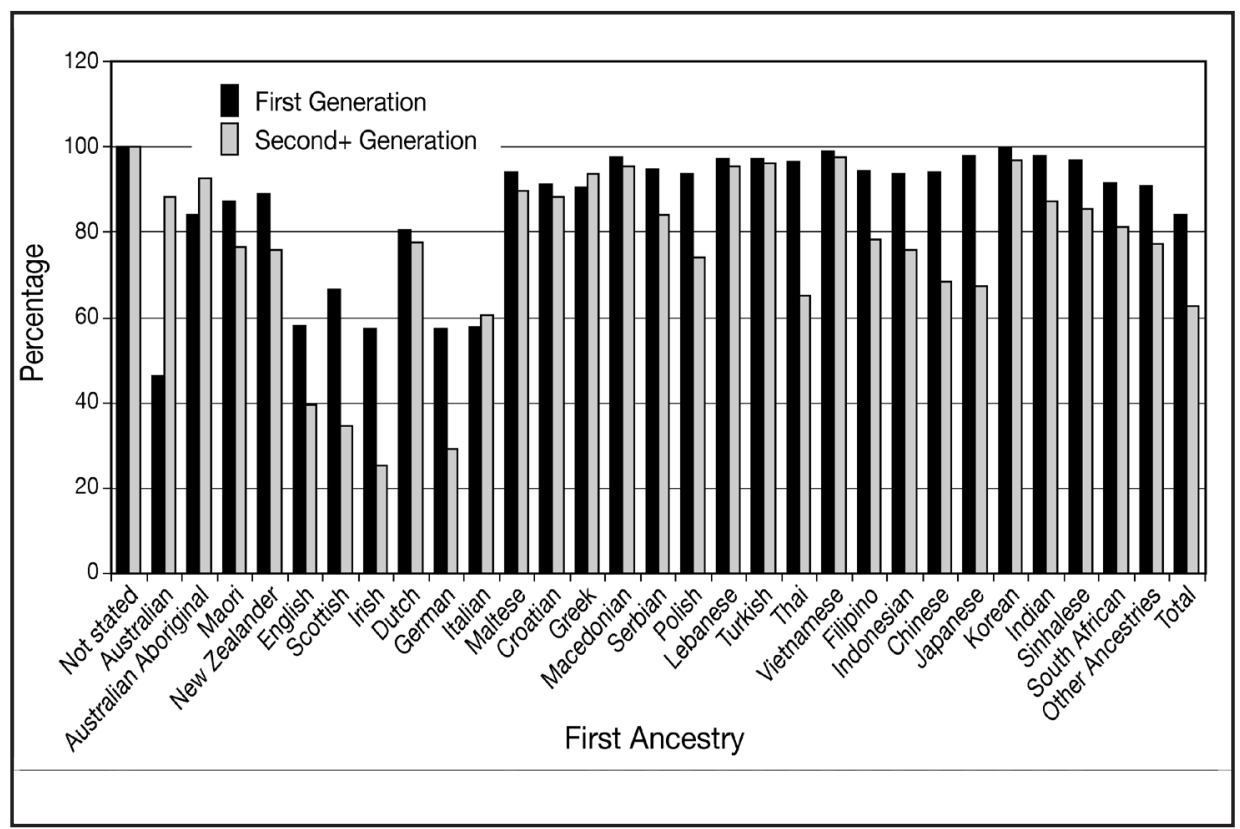

Figure 2 Single ancestry by generation (18-35), 2006

All the Australian born under 35 have grown up during a period when Australia was in the process of developing and implementing its multicultural policies. However, this is not the case for many of the overseas born who have arrived in Australia more recently. Since the end of the 20th century, there have been major changes in Australian immigration policies to provide increased opportunities for skilled settler migration as well as temporary migration for periods in excess of a year for international students and temporary workers ${ }^{28}$. One outcome has been a significant increase in the numbers of young people in many ancestry groups. By 2006, 39.7 per cent of all the overseas born aged 18-35 had arrived since 2000. Among all those aged between 18-24, 60 per cent arrived after 2000, with the figure being even higher for the Thai, Indonesian, Chinese, Japanese and Indian. The percentages were slightly lower among those in the older 25-35 year age group who are less likely to have come to study since 2000. Nevertheless, more than 60 per cent of the Thai, Japanese and Indian had arrived in this time period followed by 50 per cent of the Indonesian and 40 per cent of the Germans, Sinhalese and South Africans (Figure 3). The effect of these changes in patterns of migration means that it can no longer be assumed that all these young people now living in Australia intend to 'settle' or be 'incorporated' in the same way as earlier cohorts. For some of them, the Australian education for which they have paid substantial sums of money may be viewed as a means of obtaining an education which will allow them to secure work in other countries. For

28 The census data used in this paper includes those on temporary visas who have lived in Australia for at least one year. 
many others, Australian qualifications now make it easier to obtain permanent residence, although, in common with their Australian born peers, they too may have ambitions to travel, if not settle, overseas ${ }^{29}$.

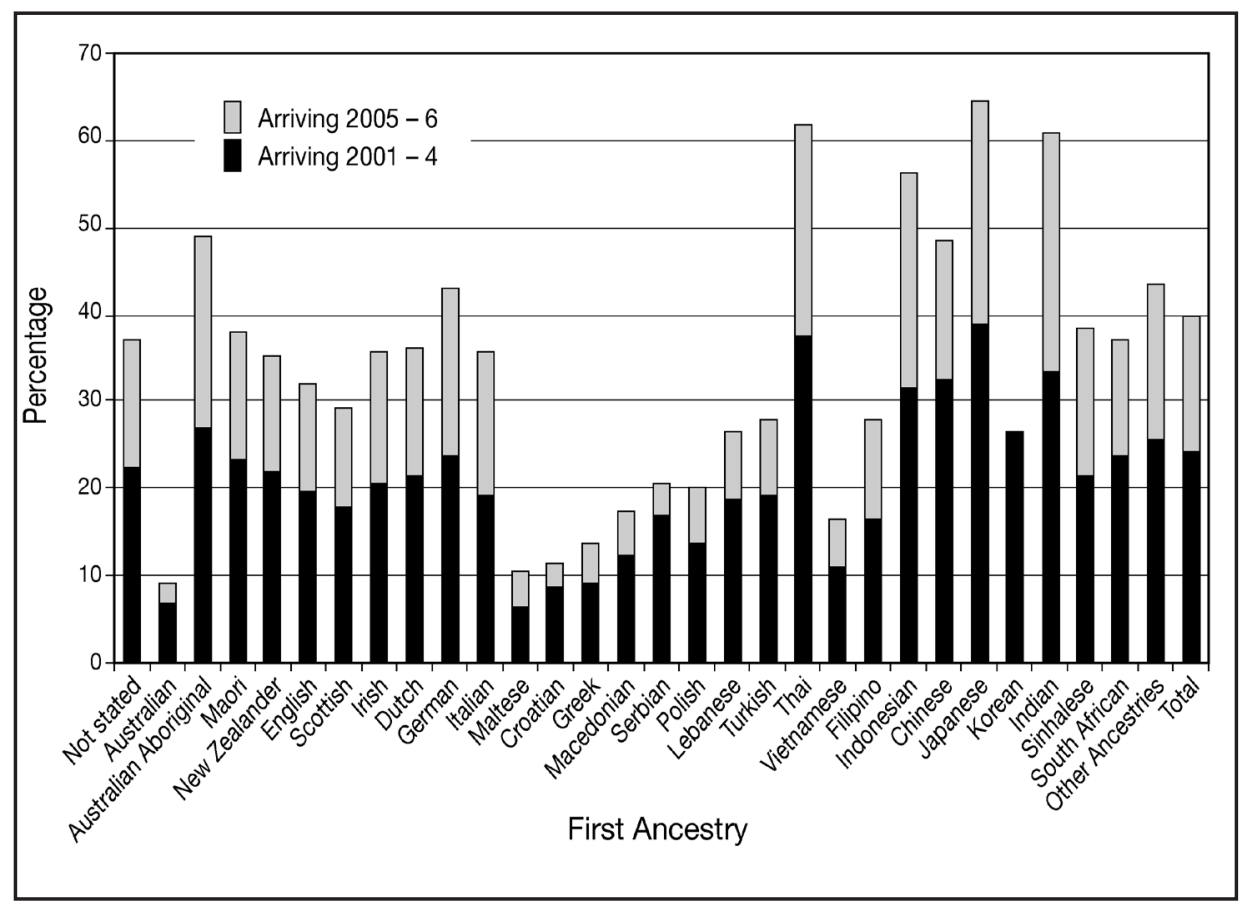

Figure 3 Ancestry and year of arrival (2001-6), 2006

Proficiency in English, the uncontested national language, is an imperative if incorporation is to involve extensive participation in the wider society. As might be anticipated, the Australian born (2+ generation) who speak a language other than English at home typically report high levels of English proficiency (Figure 4). The major exception are those of Australian Aboriginal ancestry. Among the first generation overseas born, the older, 25-35, age group (except in the case of the Italians and Japanese) are more likely than the younger overseas born to report either not speaking English at all or not speaking it well. The first generation groups most likely to report lack of proficiency in English are those of Korean, Vietnamese and Turkish ancestry.

29 In 2007-8, 27.5 per cent of all those granted permanent residency were already living in Australia on temporary visas and the percentage was even higher (28.9 per cent) in the following six months. Department of Immigration and Citizenship (2009). Immigration Update: July to December 2008. Belconnen, Department of Immigration and Citizenship, ACT: 8. 


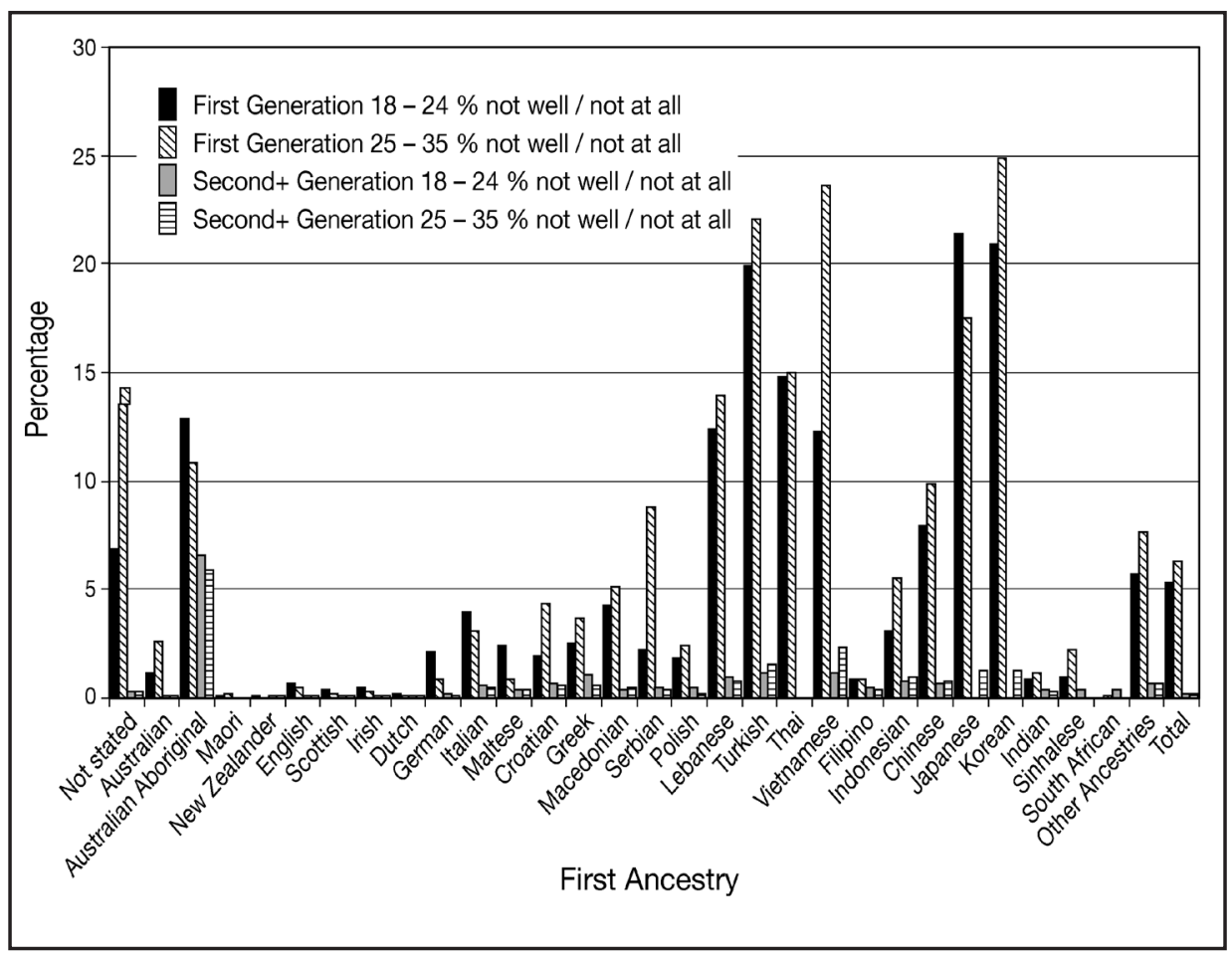

Figure 4 Lack of English proficiency by ancestry and generation, 2006

\section{Socio-economic incorporation}

One of the difficulties with many discussions of patterns of socio-economic incorporation is that they focus on the experiences of highly aggregated groups such as those from English speaking and non-English speaking backgrounds (NESB). In doing so, they gloss over the diversity which, as seen above, characterises Australia's multicultural youth. The population data from the 2006 census provides information about three dimensions of socio-economic incorporation: educational participation, lack of educational qualifications and unemployment.

Particularly among the 18-24 age group there is considerable diversity between ancestry groups in the extent of educational participation. The percentage of those who are not studying is particularly low among the first generation in those Asian ancestry groups (other than Vietnamese and Filipinos), which include substantial numbers of international students (Figure 5). Even among the Vietnamese and Filipinos the participation rate among the $2+$ generation Australian born is still higher than for most of the other ancestry groups, where usually more than 50 per cent are not continuing with their education. Among 
those aged between 25-35 the differences in educational participation have largely declined, although the tendency for lower participation among the $2+$ generation remains.

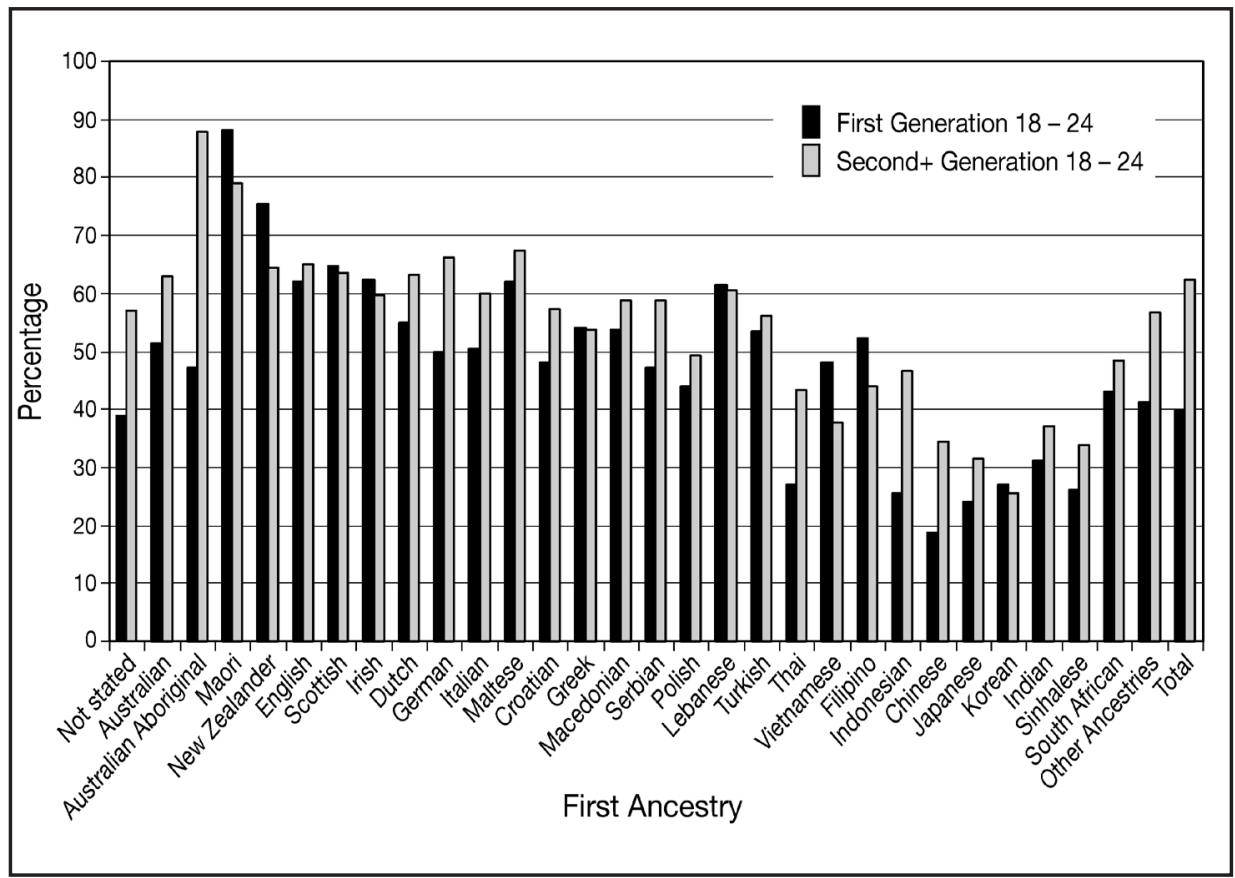

Figure 5 Not studying by generation and age (18-24), 2006

When the focus turns to those who have post-school qualifications the older, 25-35 age group, is less likely to be lacking such qualifications. However, there are generational differences between the ancestry groups (Figure 6). In some of the groups such as the Maori, Lebanese and Turkish, the overseas born first generation is more likely to be unqualified in both age groups - a pattern which suggests that growing up in Australia has contributed positively to gaining educational qualifications and 'capital'. In others, the advantage of the $2+$ generation in having qualifications is most evident among the older, 25-35 age group of Vietnamese and Filipinos.

Access to employment is one of the most critical indicators of socio-economic status. In 2006 there was substantial variation in the unemployment rate which ranged from 3 per cent for the Maltese up to almost 9 per cent for those of Turkish ancestry. Groups with above average rates of unemployment included Aborigines, Maoris, Serbians, Lebanese, Turkish and Asian ancestry groups (apart from the Filipinos and Japanese). Being Australian born does not necessarily protect against unemployment as the $2+$ generation of Turkish, Vietnamese, New Zealand, Scottish, Irish and Japanese ancestry groups all 
reported clearly higher percentage levels of unemployment than the first generation (Figure 7). One of the most noteworthy features of these patterns is that high levels of unemployment still characterise those immigrant groups (the Lebanese, Turkish and Vietnamese) and their descendents who were widely seen in their early years of settlement after their arrival in 1970s as experiencing substantial socio-economic disadvantage

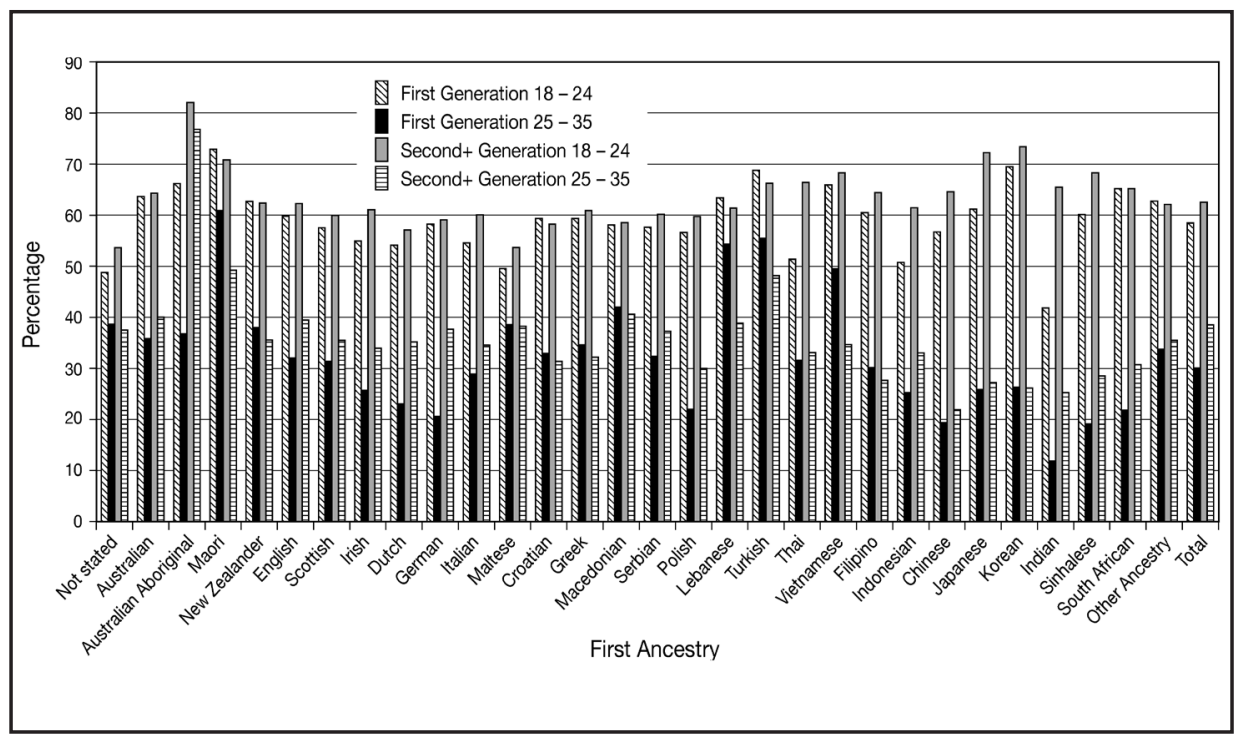

Figure 6 Lack of post-school qualifications by age and generation

Three factors are often suggested to influence access to employment: level of qualifications, fluency in English and year of arrival. Of the three the census data indicates that possessing a post-school educational qualification is the most important factor in avoiding unemployment (Figure 8). Given that substantial numbers of young people have been born and raised in Australia and/or come from predominantly English speaking countries, it is not altogether surprising that in only a few ancestry groups, such as the Serbian, Lebanese, Turkish and the various non-Filipino Asian ancestry groups, is there evidence that lacking English proficiency is a major factor associated with unemployment. It is often thought that length of residence in Australia is associated with declining levels of unemployment since over time individuals improve their English and acquire the social and cultural capital necessary to access the labour market. Length of residence does appear important in reducing unemployment among more recently arrived Asian ancestry groups. However, this is not so evident in the longer established ancestry groups where the Australian born are a significant component of the total numbers unemployed. 


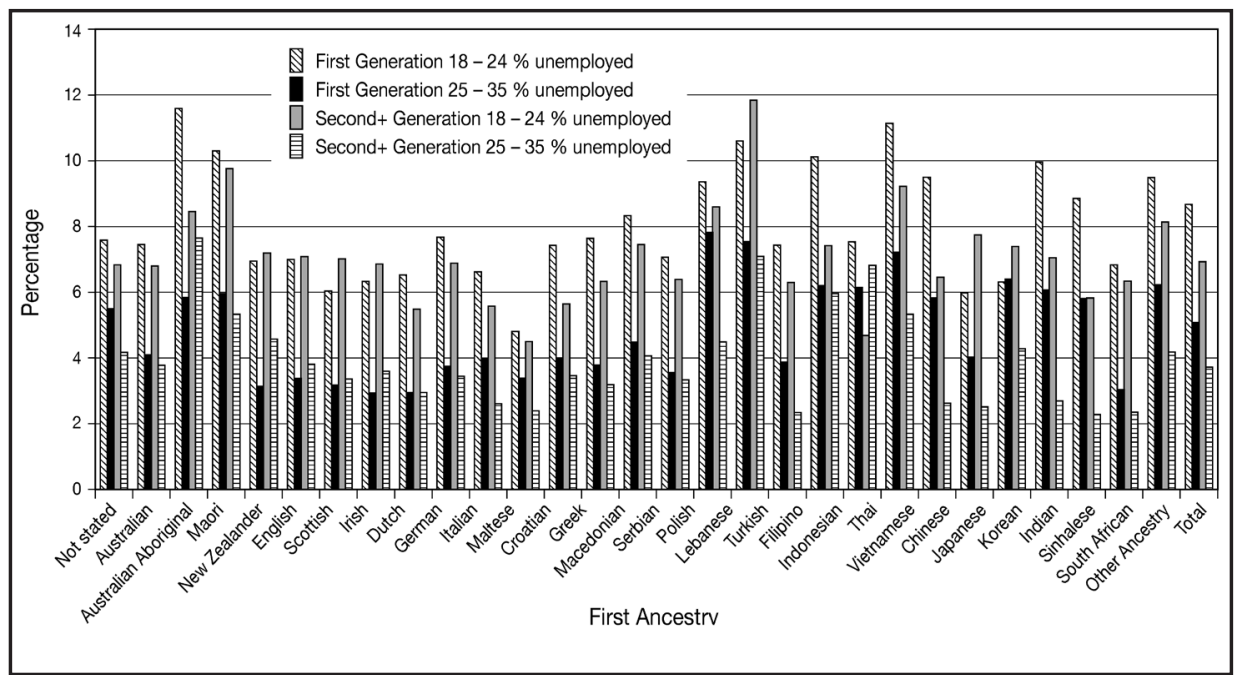

Figure 7 Unemployment by generation (18-35), 2006

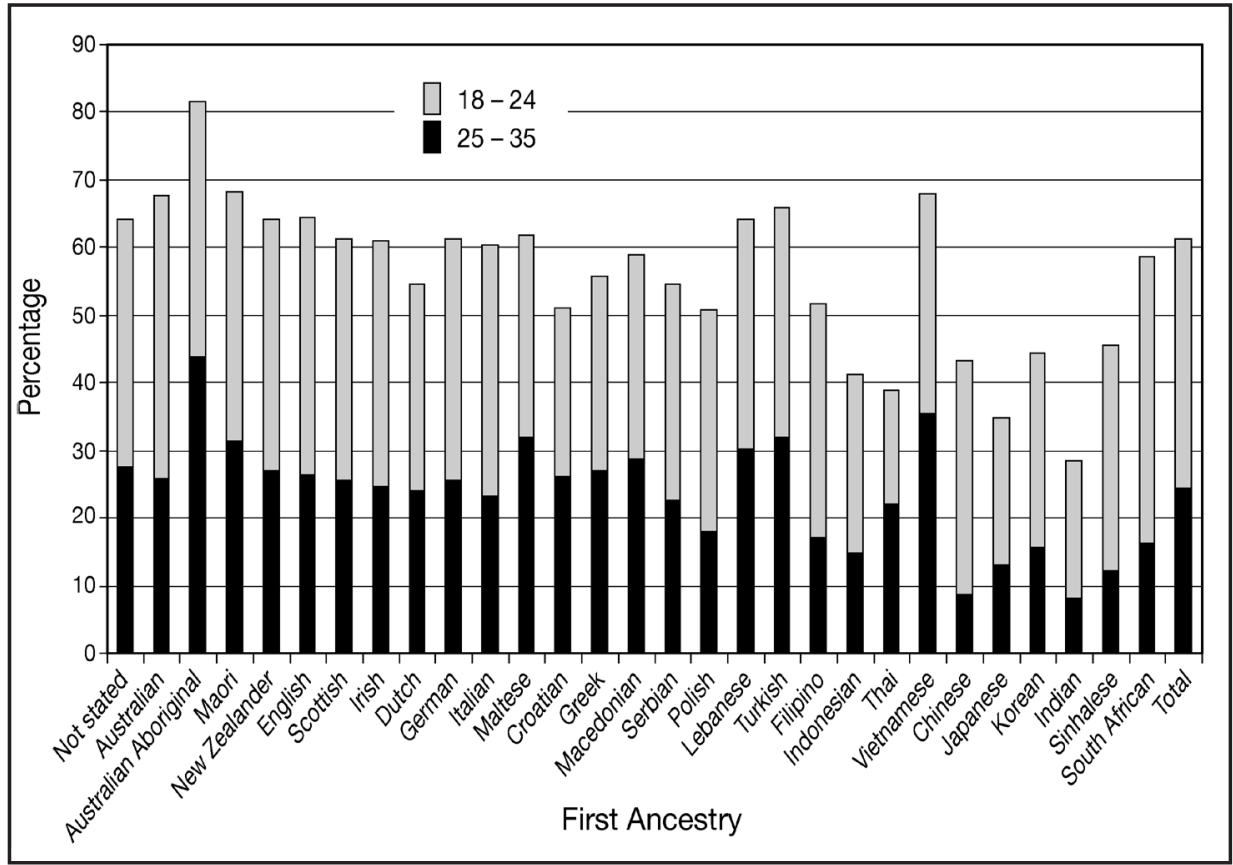

Figure 8 Unemployment by lack of qualifications by age, 2006

Although there is considerable variation in the economic and educational outcomes just described for young people from different ancestries in Australia in 2006, analyses using 1 per cent census sample data from the 2001 census indicated that by the second and third generations there was considerable 
convergence across the majority of ancestry groups which were examined ${ }^{30}$. This convergence suggests that being born and raised in Australia does contribute to a decline in the 'ethnic penalties' experienced by the first generation. The main exception, apart from Aboriginal Australians, after taking account of age, educational level and marital status was among second-generation Lebanese men and women who were more likely to experience unemployment. However, among this group in 2001 there was evidence of a bipolar pattern since there was little evidence that those who were employed experienced disadvantage relative to other ancestry groups in their occupations and incomes

Given that a major impetus for the adoption of multicultural policies in Australia was a concern to overcome socio-economic disadvantage, the evidence relating to the socio-economic dimension of contemporary incorporation is generally positive in international as well as national comparisons. This was illustrated in the 2007 Inglis and Model study which was part of a thirteen nation study of ethnic minorities in Western labour markets. The editors of that study concluded that Canada and Australia, both of which have a long standing commitment to multicultural policies, emerge as the two countries where the ethnic penalties for immigrant minorities are least evident ${ }^{31}$. However, the experiences of their Indigenous minorities, among whom multicultural policies have not been pursued, are far less favourable and closer to those of guest worker groups in various European countries.

The sustainability of these patterns of incorporation in the face of changes in the economic and social environment needs to be continually monitored. By 2006 the Australian levels of unemployment had improved and preliminary analysis of the comparable 2006 census data suggests that these findings from 2001 will be largely confirmed. Since then, the global financial crisis beginning in 2008 has led to some increase in Australia's levels of unemployment although it is yet too early to see whether this is affecting some ethnic groups more than others.

\section{The social dimension of incorporation}

One of the difficulties of assessing the social incorporation of multicultural youth in Australia is the absence of national data covering such diverse aspects of their social experiences as their friendship groups, leisure activities and participation in community organisations and associations. An exception is a recent paper

\footnotetext{
30 Inglis, C and Model, S (2007). Diversity and Mobility in Australia, in A Heath and S Y Cheung (eds), Unequal Chances: Ethnic minorities in Western labour markets. Oxford University Press, Oxford for the British Academy. Because of small sample sizes the socio-economic outcomes could only be examined for the larger of the ancestry groups described in more detail in the text.

31 Heath, A and Cheung, S Y (eds) (2007), Ibid.
} 
which analyses the 2006 General Social Survey in relation to the social resources of young people ${ }^{32}$. The paper is based on 2175 individuals aged between 1829 from three groups: the Australian-born (84 per cent of the sample) and permanent Australian residents born either in mainly English speaking (MES) countries ( 5 per cent) or in other countries (11 per cent). Although the sample size only allows a comparison between these two groups of the overseas-born and does not provide information about the second generation from different ethnic backgrounds, it nevertheless provides an important base-line set of data giving insights into selected aspects of the social lives of young people.

One of the study's key findings is that youth from mainly English speaking countries have similar forms of social connectedness to their Australian-born peers. This includes visits with friends over the last three months, frequency of contacts with family and friends, social activity on the internet, remaining close to former family household members, having close family and friends in whom to confide, an ability to ask for small favours and get support in times of crises. Unemployment appears associated with more restricted, and perhaps less well-resourced, social networks. This finding is an important reminder that both education and work have important contributions to make which extend beyond their instrumental contribution to gaining skills, knowledge and material resources. All young people surveyed felt equally likely to approach government agencies and non-government organisations for assistance, although few had actually done so. Instead, family members and friends are more important sources of support than impersonal groups or institutions.

One surprising finding of this study is that young people from non-English speaking backgrounds apparently feel less able to call on family members for support in times of crisis. This finding conflicts with common assumptions (and indeed some of the data reviewed below) about the existence of tight-knit family bonds in many immigrant communities. One possible explanation is the existence of intergenerational conflict within NESB families ${ }^{33}$. Others may be the families' lack of material resources or more generally attenuated social links with immediate family members in Australia or overseas.

As already noted, much of the research on ethnic minority youth has focused on the problematic nature of their experiences in Australia through research on youth 'gangs', particularly among those from Lebanese, Arabic or Muslim backgrounds in disadvantaged areas in western Sydney. This research highlights the social and material disadvantage experienced by the young people and problematises the extent to which they are actually involved in criminal gangs.

32 Khoo, S E (2009). Migrant Youth and Social Connectedness, in F Mansouri (ed), Youth identity and migration: Culture, values and social connectedness, Common Ground Publishing, Melbourne: 165-177.

33 Ibid: 171. 
However, it also depicts them as resisting mainstream society as they search for a secure identity, respect and material resources. How they do this is shown to be potentially counter-productive as they risk being marginalised from that society as well as from their own families and communities. More recent research, which revisits one of these small groups of young men after nearly a decade, shows that the dangers of marginalisation and non-incorporation evident in their earlier lives has not, however, eventuated as they are now 'respectable' educated and employed adults ${ }^{34}$. Other research, also drawing on the experiences of young people from diverse ethnic backgrounds in western Sydney, provides a more varied picture of the ways in which they participate in society and their daily activities ${ }^{35}$. Together with other studies ${ }^{36}$ there is now emerging a more nuanced understanding of the varied forms of social incorporation characterising Australia's multicultural youth and how ethnicity, gender, class and locality all play a part in contributing to the complexity in their patterns of incorporation.

In the case of Middle Eastern groups such as Lebanese and Turks, which have a long history of being viewed as 'outsiders' even predating events such as the War on Terror and the Cronulla riots ${ }^{37}$, it is important to avoid assuming that their patterns of social incorporation necessarily involve either withdrawal and looking inward for protection or actively resisting the wider society. As recent research into the experiences of second generation Lebanese and Turkish youth is showing, the nature of their social incorporation is more complex ${ }^{38}$. The 306 hour-long interviews were undertaken in 2008 in Sydney and Melbourne among young (18-35 year old) Australians from second generation Lebanese (Christian and Muslim) and Turkish backgrounds as well as a third generation group both of whose parents were born in Australia.

When the young people reported on their current group of friends, the majority of the third-generation group ( 80 per cent) said that many or most of their friends were of Anglo-Celtic background. Among the second-generation groups, onethird of the Turkish and Christian Lebanese group and a quarter of the Muslim Lebanese also reported that most or many of their friends were Anglo-Celtic.

\footnotetext{
34 Noble, G (2007). Respect and Respectability amongst Second-Generation Arab and Muslim Australian Men, Journal of Intercultural Studies, 28 (3 August): 331-344.

35 Butcher, $\mathrm{M}$ and Thomas, $\mathrm{M}$ (2003). Op cit.

36 Gilbert, H, Khoo, T and Lo, J (eds) (2000). Diaspora: Negotiating Asian-Australia, St Lucia: University of Queensland Press; Guerra, C and White, R (1995). Op cit.

37 McAllister, I and Moore, R (1989). Ethnic Prejudice in Australian Society: Patterns, intensity and explanations. Office of Multicultural Affairs, Canberra.

38 The study was funded by the Department of Immigration and Citizenship and the preliminary findings referred to here were presented at a conference in Amsterdam in December 2008. Inglis, C (2008). The Integration of the Australian Second Generation. Paper presented at the TIES Academic Conference from http:// www.tiesproject.eu/component/option,com_docman/task,cat_view/gid,131/Itemid,142/.
} 
The extent of mixing across ethnic groups had increased when compared to their friendship groups in secondary school and suggests that after school there are more opportunities to meet and develop more ethnically diverse friendships.

While it may see somewhat paradoxical in the light of recent events, two thirds of the second-generation Turks, half of the Christian Lebanese and almost half of the Muslim Lebanese described relations between Anglo-Celts and their own groups as 'friendly' or 'very friendly'. However, this positive assessment was stronger in Melbourne than in Sydney where the events linked to the Cronulla riots in 2005 remain in people's memories as indicated by the way a higher percentage of Sydney than Melbourne respondents from all groups also felt that these friendly relations had declined between their own group and Anglo-Celts in Sydney over the past year. Perhaps as a reflection of their limited personal contacts with people of Lebanese and Turkish backgrounds, the third-generation group were less likely to view relations as 'friendly' with these groups. Indeed, many said that they were 'indifferent' to the nature of the relationship with the Lebanese or Turkish groups.

Although not necessarily sharing the same friendship groups, all the groups had quite similar types of involvement with formal organisations over the previous year. Two-thirds had been involved with organisations and in many cases this brought them into contact with others from different ethnic backgrounds. The most popular organisations were those involved in sport (particularly among the young men), followed by artistic, musical and cultural organisations and then those with a religious focus which were more popular with the young women. The involvement with religious organisations was most likely to involve mixing within the young people's own ethnic community (59 per cent) whereas involvements in cultural (32 per cent) and sporting (28 per cent) organisations was more likely to involve mixing outside their ethnic community.

When describing the ethnic composition of their local neighbourhood there was evidence that the third generation was more likely to be isolated from those of NESB background; this was reinforced as 25 per cent said they lived in suburbs where almost nobody in the area was NESB. Even so, 10 per cent described their suburb as one where almost everyone was NESB. In itself, this is a reflection of the diversity of Australian suburbs. It may also reflect the gentrification of inner-city working class suburbs which have become popular with young professionals from Anglo-Celtic backgrounds. Of all the groups, the Muslim Lebanese (32 per cent) were most likely to live in neighbourhoods consisting entirely of people from NESB backgrounds.

One issue which potentially affects the young people's attitudes to society concerns their responses to socio-cultural diversity. More than two-thirds of all interviewees felt that living together with people of different origins was 
enriching, rather than threatening, for their own culture. The group expressing less certainty about this were the Muslim Lebanese women, only one-third of whom saw the experience as enriching. When individuals were given the opportunity to actually implement this positive evaluation by indicating their preferred residential area the findings were a little different. More than half of the third generation and of the Turks said it made no difference to them. The figure was slightly lower for the Lebanese although there was some indication that the Christian Lebanese in Sydney would prefer to live in a neighbourhood where almost nobody was of NESB origin. In contrast, 20 per cent of the Sydney Muslim Lebanese, who of all the groups in this study have been the object of greatest negative media and public scrutiny, indicated a preference for living in a neighbourhood where the majority of the population were of NESB background, perhaps because they felt this would involve less hostility and threats. However, this was still less than the one-third who actually lived in such neighbourhoods. And a similar disjuncture between preference and reality was also noted amongst the Sydney Turks

These findings, which indicate that the second generation are more likely to have close social contacts with those of Anglo-Celtic background than vice versa, are similar to those reported in Butcher and Thomas' study of youth culture. They noted that the young people of non-Anglo Australian background were actually more 'multicultural' in their range of social contacts and activities than were those from Anglo-Australian backgrounds ${ }^{39}$.

Social incorporation is, however, a two-way process involving minority and the majority groups. Despite evidence of friendship patterns and participation in social and community activities, the existence of negative stereotypes, prejudice and discrimination can constitute barriers to the acceptance and participation of minority groups in the wider society. Since, in Australia, Muslims, and those of Lebanese background, have been particular targets of hostility from the media and other sections of the community we asked them whether they had experienced hostility or unfair treatment because of their origins or background. Somewhat surprisingly some 40 per cent of all the second-generation groups, compared with three-quarters of the third generation, said they had never had such experiences. Women were less likely to report such experiences than men. This raises the questions as to whether this is because they are less likely to venture outside their own circle of friends than are the young men. Certainly our interviewees rarely reported experiencing hostility or unfairness in their local neighbourhood. This was in contrast to when they went out for entertainment or to restaurants where they also were more likely to report hostility or unfair

39 Butcher, M and Thomas, M (2003). Op cit: 15. 
treatment than in encounters with the police. Of all the groups, the Muslim Lebanese young men were most likely to report negative experiences in their socialising and in their contacts with the police.

Muslim Lebanese men were the group least likely to report they had 'never' been the victims of discriminatory experiences, yet even 39 per cent of them reported the absence of such discrimination. It appears that within this group there is an important divergence of experience since 17 per cent also reported that they regularly or frequently experienced hostility or unfair treatment from the police. This was a far higher rate than for the other second-generation groups of Turkish ( 8 per cent) and Christian Lebanese ( 6 per cent). Even so, 57 per cent of the Muslim Lebanese reported they had never had such experiences with the police, a figure comparable to that for the Christian Lebanese and Turkish but still well below the figure of 90 per cent among the third generation.

The two main explanations for experiencing hostility were ethnic origin or background and religion. The latter reason was most likely to be mentioned by Muslim Lebanese and Turks and, in particular, the young women from these groups. Among the women who wore headscarves 71 per cent of the Muslim Lebanese and 67 per cent of the Turks mentioned religious discrimination. This was almost double the rate for explanations in terms of ethnic origin or background (43 per cent and 33 per cent respectively).

Two other locations where discrimination is often mentioned are schools and the labour market. Secondary school was the most likely location for all reported experiences of hostility and unfair treatment. Half of the Turkish and Lebanese groups and one-quarter of the third-generation group reported that they had experienced such treatment in their secondary schooling. Among those who were employed, workplace-related experiences were lower. The highest rates of hostility and unfair treatment were reported by those from Muslim Lebanese backgrounds, only 39 per cent of whom reported never experiencing workrelated discrimination compared with 11 per cent of the third generation, 21 per cent of Turkish and 33 per cent of Christian Lebanese.

Assessment of the social dimensions of incorporation of Australian ethnic groups is more complex than their socio-economic incorporation. Even when examining second-generation groups such as the Lebanese and Turks on a restricted range of social indicators, it is apparent that these groups, which are particularly likely to be the targets of hostility and discrimination, actually are incorporated in a manner characterised by participation in the wider Australian society. That said, they are more likely to have contacts with NESB minority background groups than with the dominant Anglo-Celtic majority. Even so, it appears they are actually less 'isolated' in the range and diversity of their social 
contacts than are members of the predominantly Anglo-Celtic third-generation majority whose friends and residential areas are more homogeneous and less likely to include those from non-English-speaking backgrounds.

\section{Identity and belonging}

Citizenship is often cited as a measure of attachment or belonging to a society. However, given the instrumental benefits which are attached to citizenship, both domestically and when travelling internationally, legal citizenship is, at best, a proxy for other ways of assessing attachment or identification ${ }^{40}$. Second-generation Australians automatically have Australian citizenship and, in some instances, also the citizenship of their families' country of origin. First generation migrants however need to take active steps to gain Australian citizenship. Although it does not provide information on the eligibility of the first generation to acquire Australian citizenship, data from the 2006 census does indicate the variation between first-generation ancestry groups in the extent to which they have acquired Australian citizenship (Figure 9).

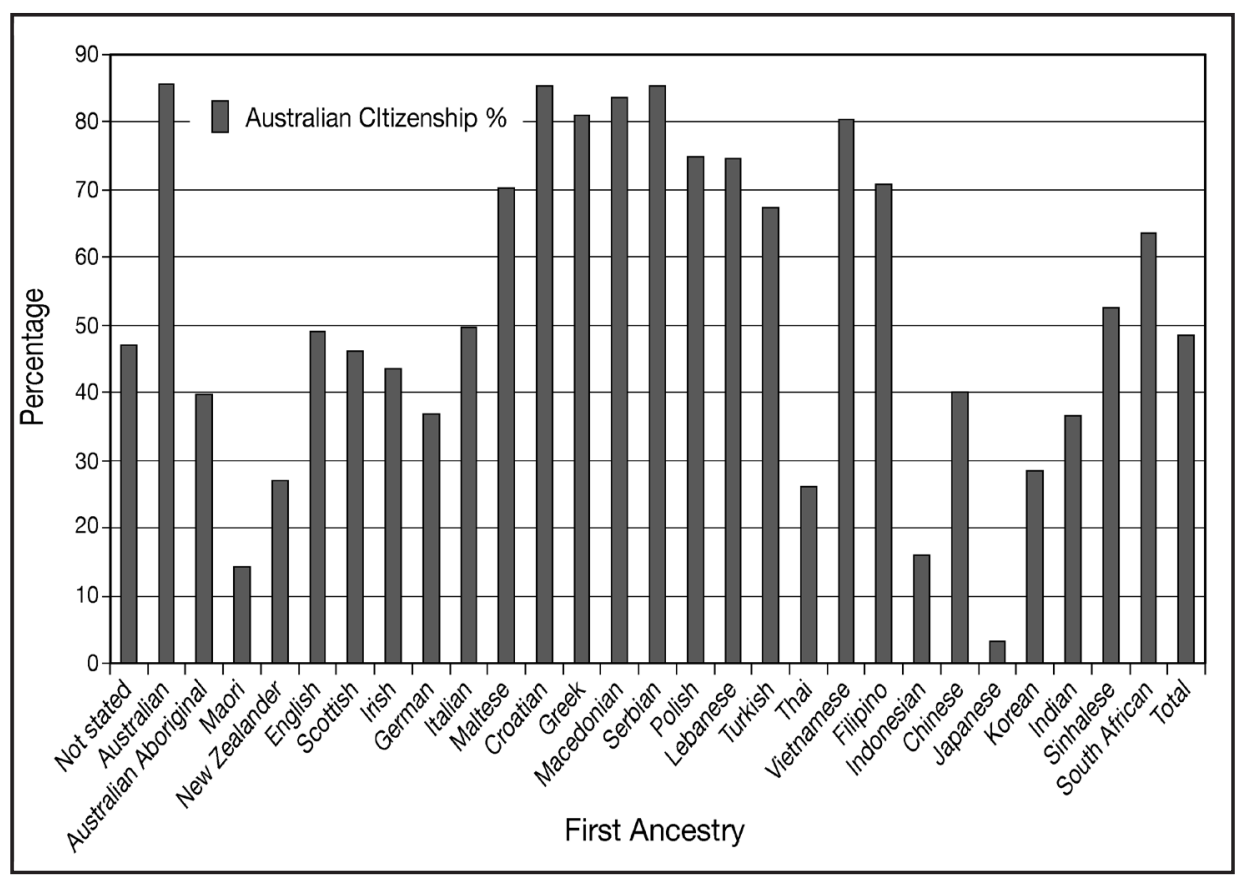

Figure 9 Overseas born with Australian citizenship, 2006

40 Ip, D F, Inglis, C and Wu, C-T (1997). Concepts of Citizenship and Identity Among Recent Asian Immigrants in Australia. Asian and Pacific Migration Journal, 6 (3-4): 363-384. 
A better indicator of attachment or belonging than citizenship is how an individual identifies themselves in various social situations. Important though inequality and disadvantage are in affecting inter-ethnic relations, the incorporation of minority groups into societies also involves a variety of other, often more subtle, factors including perceptions of acceptance and discrimination. Jeff Reitz and Rupa Banerjee have highlighted the importance of these dimensions in their analysis of Canadian data which shows that, although as in Australia important steps have been made towards overcoming social and economic disadvantage, many groups still perceive themselves as lacking acceptance and being socially marginalised. This, in turn, has affected their sense of identity and belonging within the larger society and has the potential to negatively affect inter-ethnic relations and social cohesion ${ }^{41}$. Much of the literature on Australian ethnic minority youth, especially young Lebanese men, has highlighted their desire for respect and acceptance ${ }^{42}$.

When asked about their identification with a religious identity it was apparent that many of the Muslim Lebanese and Turks identified strongly or quite strongly as Muslim. This was in contrast to the predominantly Christian third generation and, to a lesser extent, the Christian Lebanese who are more likely to strongly identify as Christians than the third generation. The Lebanese commitment to a Christian or Muslim identity hence needs to be seen as framed not only by Australian but, also, Lebanese society where confessional differences are embedded in the country's constitution and much of daily social life.

Despite the negative experiences reported by the Lebanese and Turkish young people in the present study, a majority of both the second-generation and the third-generation groups stated that they strongly or very strongly identify as 'Australian'. The strength of this identification is only slightly below their far less problematic identification with the city where they live, whether it is Sydney or Melbourne. Especially in the context of the recent tendency to 'demonise' Islam in many sections of Australian public discourse, the strength of their identification with Australia is surprising, especially as it also is found among those who strongly identify with their Muslim background as well as

\footnotetext{
41 Reitz, J and Banerjee, R (2007). Racial Inequality, Social Cohesion, and Policy Issues in Canada. Belonging? Diversity, Recognition and Shared Citizenship in Canada. In K Banting, T J Courchene and F L Seidle (eds), Belonging? Diversity, Recognition and Shared Citizenship in Canada, Montreal Institute for Research on Public Policy, Montreal: 489-545.

42 Butcher, $\mathrm{M}$ and Thomas, M (2006). Ingenious: Emerging hybrid youth cultures in western Sydney, in P Nilan and C Feixa (eds) (2006), Op cit: 53-71; Butcher, M and Thomas, M (2003). Op cit; Dunn, K M, Forrest, J, Burnley, I and McDonald, A (2004). Constructing racism in Australia. Australian Journal of Social Issues, 39 (4): 409-430; Noble, G (2007). Op cit; Noble, G, et al (1999a), Op cit; Noble, G, et al (1999b). Op cit; Noble, G, Poynting, S and Tabar, P (1999b). Youth, Ethnicity and the Mapping of Identities: Strategic essentialism and strategic hybridity among male Arabic-speaking youth in South-western Sydney. Communal/Plural, 7, 1: $29-44$.
} 
their 'Turkish' or 'Lebanese' identity. This finding was in marked contrast to those reported from the parallel studies in many of the European countries such as the Netherlands, Germany, Austria, Sweden, France, Belgium and Switzerland ${ }^{43}$.

These findings cannot be explained by differences in the way the Australian and European studies asked about religious, ethnic or national identities since the same questions were used. What is different is that the official discourse on Australia as a multicultural society comprising individuals from many diverse backgrounds provides a 'space' which accepts and includes those who are not from the majority Anglo-Celtic background. This is so even if, in colloquial usage, it is not uncommon for individuals from other backgrounds to distinguish themselves from 'the Australians' or 'Aussies', especially when referring to patterns of behaviour or cultural practices and beliefs, such as those concerning the strength of family ties, where they consider their own to be superior.

Although globalisation and transnationalism have frequently been invoked as processes which may distance young adults from a sense of belonging and identification with their country of residence, this does not appear to be the case among the second-generation Lebanese and Turkish youth. Almost all these young people use the internet which gives them the opportunity to explore and establish overseas contacts. More than half of them have also had at least one visit to their parents' homeland in the last five years, usually for a holiday and/or family reasons. A quarter of the Turks and Christian Lebanese also have sent money back as have 40 per cent of the Muslim Lebanese. Yet, these activities co-exist with a strong Australian identity. Nor was their any indication that they were associated with plans to spend more than a year in the parents' homeland, as a majority have no such plans. A definitive 'certainly not' response was most likely to be given by the Christian Lebanese (76 per cent), followed by the Muslim Lebanese (67 per cent) and the Turkish (56 per cent). In fact, only between 2 per cent and 6 per cent had definite plans to spend more than a year in their parents' homeland. Again it appears that among the young second-generation interviewees, the transnational ties co-exist with a continuing intention to see Australia as their home, consistent with their strong identity as 'Australian'. 


\section{Conclusion}

The diversity of the ethnic backgrounds and experiences of migration among young Australians is typical of the multicultural nature of the whole society. It also makes a general assessment of their incorporation or integration into Australian society more complex. Changing immigration policies, source countries and global changes all affect how they are incorporated. Neither ethnic group, generation, length of residence nor migration status can alone explain the patterns found, although there is greater uniformity in the experiences of the Australian-born than there is among the overseas-born. One effect of the adoption of multicultural policies is that they have shifted attention to the response by Australian institutions and society towards minority groups as being important in individuals' integration into the society. These policies have not managed to eliminate discrimination nor prejudice. They have the potential to result in a problematic form of incorporation in which, while individuals live in Australian society, their ability to participate and feel included differs in quality and extent from the majority population. Certainly, much of the recent youth research has been couched in terms of the problems confronting young people from ethnic minority backgrounds and implies that their incorporation into Australian society is highly problematic. The absence of research on 'non-problematic' young people has resulted in a lack of alternative perspectives from which to evaluate their experiences and assess the extent of their incorporation into Australian society.

While only able to explore selected dimensions of incorporation in this chapter, the shift in focus towards a broader cross-section of young people gives no basis for concluding that multiculturalism has undermined their level of incorporation and integration or led to threats to social harmony. In terms of the socio-economic dimensions of integration, the findings suggest that inequality is far less among ethnic groups in Australia than in most other comparable countries. Although the data used to assess the social integration of young people is more limited, it is consistent with other research that shows those from ethnic minority backgrounds are actually more likely to be involved in ethnically diverse social networks than those from third-generation, majority backgrounds. Regrettably, discrimination and prejudice are part of the experiences of many young people. Despite this, and despite their maintenance of a variety of transnational linkages overseas, there is evidence from Australian-born young people, whose origins are in Lebanon and Turkey, that their identification with Australia coexists with their distinctive ethnic and religious identities. Since both groups are often identified as having a problematic experience of incorporation this is a positive outcome. 
Apart from specific policy initiatives, multiculturalism's inclusive construction of Australian society appears to have contributed to integration, which in turn has expanded the boundaries of multicultural Australian society. However, it also is important to acknowledge the extent to which they have approached and overcome a variety of difficulties and barriers to achieving such a level of integration. Whether similar findings about the ability of multiculturalism to contribute to integration can be sustained in studies which include a more detailed examination of the dimensions of incorporation, and groups from a wider range of diverse ethnic origins, is still to be determined. 